Received: January 12, 2016

\title{
Comparing Attention Deficit Hyperactivity Level with the Work Experiences of Nurses Working at a Private Hospital in Istanbul
}

\author{
Gözde Demirelli ${ }^{1}$ \\ Istanbul Bilim University
}

\author{
Birkan Tapan ${ }^{2}$ \\ Istanbul Bilim University
}

\begin{abstract}
The most important factor in the healthcare industry is focusing on customer satisfaction and patient care. This article aims to prevent malpractice resulting from inattentiveness and to incorporate the use of attention deficit/ hyperactivity tests in the application process for healthcare staff. This study compares the attention deficit/ hyperactivity level and the work experience of nurses in a private hospital. The attention deficit/hyperactivity level of 35 nurses in Istanbul was measured using the MOXO test and compared in terms of their work experience; two groups were created based upon this characteristic. Those nurses with five or less years of work experience $(n=21)$ were expected to perform better in attention, timing, impulsiveness, and hyperactivity than nurses with more than five years of work experiences $(n=14)$. The results show that nurses with five or less years of work experience were found to perform better in attention than those nurses with more work experience. However, those nurses with five or more years of work experience were found to perform better in timing, impulsiveness, and hyperactivity than their less-experienced coworkers.
\end{abstract}

Keywords

Comparison • Attention deficit hyperactivity level $\bullet$ Nurses $\bullet$ Work experience $\bullet$ Private hospital

1 Correspondence to: Gözde Demirelli (PhD), Department of Health Administration, Institute of Social Sciences, Istanbul Bilim University, Istanbul Turkey. Email: gozde.demirelli@istek.org.tr

2 Department of Health Administration, Institute of Social Sciences, Istanbul Bilim University, Istanbul Turkey. Email: birkan.tapan@istanbulbilim.edu.tr

Citation: Demirelli, G., \& Tapan, B. (2016). Comparing attention deficit hyperactivity level with the work experiences of nurses working at a private hospital in Istanbul. Sanitas Magisterium, 2, 121-140. http://dx.doi.org/10.12738/SM.2016.2.0010 


\section{Attention Deficit Hyperactivity Disorder}

Attention deficit hyperactivity disorder (ADHD) is a common disorder among children that prevails through adolescence and adulthood. The common symptoms of ADHD are the inability to focus, concentrate, and control behavior (U.S. Department of Health and Human Services, National Institute of Mental Health, 2008).

ADHD is a neuro-biological condition observed in 5-8\% of school children (American Academy of Pediatrics, 2000; American Psychiatric Association, 2000; Centers for Disease Control and Prevention, 2003; Froehlich, Lanphear, Epstein, Barbaresi, Katusic, \& Kahn, 2007; Mayo Clinic, 2001, 2002; Surgeon General of the United States, 1999). In 4\% of these cases, ADHD persists into adulthood (Faraone, Biederman, \& Mick, 2006; Kessler et al., 2006; National Resource Center on AD/HD, 2008). ADHD affects children, adolescents, and adults of all ages; is a lifelong disorder; and affects individuals from different sexes, races, and cultures. In most cases, ADHD is observed as genetically inherited (National Resource Center on $\mathrm{AD} / \mathrm{HD}, 2008$ ).

When individuals suffering from ADHD do not receive the necessary diagnosis and treatment, they may experience certain events and hurdles as follows:

a) Academic failure

b) Inability to fulfill chores or responsibilities such as paying bills

c) Marital problems or divorce

d) Depression

e) Relationship problems

f) Substance abuse

g) Committing crime

h) Accidents

i) Inconsistent job performance or job loss

j) Chronic stress and worry due to lack of reaching goals or fulfilling responsibilities

k) Chronic and intense disappointment

1) Guilt (National Resource Center on AD/HD, 2008)

m) Problems in social relationships

n) Anti-social behavior

o) Teenage pregnancy

Therefore, early diagnosis and treatment of ADHD is crucial. 
Prevalence. Studies done in ten different countries, including the U.S., the Netherlands, Lebanon, and Mexico, have shown that the prevalence of ADHD in adults is $3-5 \%$ (Kooij, 2013).

Symptoms. The common symptoms of ADHD are as follows:

a) Short attention span

b) Being easily physically irritable or hyperactive

c) Intense impulsiveness (non-stop talking or uncontrolled movement)

d) Difficulty in starting and finishing work

d) Forgetfulness

e) Difficulty in organization, planning, and time-management (National Resource Center on $\mathrm{AD} / \mathrm{HD}, 2008)$.

\section{Types.}

\section{Predominantly inattentive type (ADHD - I)}

An individual who suffers from this type of ADHD, experiences the following symptoms:

a) Difficulty paying attention to details, resulting in reckless mistakes

b) Difficulty in concentrating

c) Difficulty in listening to someone

d) Difficulty in following multistep directions

e) Tendency to be disorganized

f) Avoids work that requires constant cognitive effort

f) Loss of possession

g) Forgetfulness (National Resource Center on AD/HD, 2008).

\section{Predominant hyperactive - impulsive type (ADHD - HI)}

An individual who suffers from this type of ADHD shows the following symptoms:

a) Constant fidgeting (moving fingers and/or feet while sitting)

b) Difficulty in staying seated for a long time

c) Has trouble doing work quietly 
d) Over talks

e) Responds to a question before it is finished

f) Finds it challenging to wait in line

g) Interrupts or intrudes upon others (National Resource Center on AD/HD, 2008).

\section{Combined type (ADHD - C)}

In this type of disorder, the individual displays both inattentive and hyperactiveimpulsive symptoms (National Resource Center on AD/HD, 2008).

Etiology. Although the etiology of ADHD is not certain, genetic (Neale, Medland, Ripke, \& Anney, 2010; Neale, Medland, Ripke, Asherson et al., 2010); neurobiological (Castellanos et al., 1996; Shaw et al., 2012; Volkow et al., 2009); and environmental factors (Bhutta, Cleves, Casey, Cradock, \& Anand, 2002; Froehlich et al., 2009; Grizenko et al., 2012; Sagiv, Epstein, Bellinger, \& Korrick, 2013) are observed as the causes of ADHD (Shire: ADHD Institute, 2014).

Genetic inheritance. An analysis of 20 twin studies indicated that $76 \%$ of these disorders are attributable to genetics. Later, a systematical analysis stated that the genetic factor is $70 \%$ (Faraone et al., 2005).

ADHD is usually defined as a neuro-biological disorder which has been linked to structural (Ivanov et al., 2010; Kobel et al., 2010; Valera, Faraone, Murray, \& Seidman, 2007), functional (Dickstein, Bannon, Castellanos, \& Milham, 2006), physiological (Liotti et al., 2007; Quintana, Snyder, Purnell, Aponte, \& Sita, 2007; Synder \& Hall, 2006), and chemical (Costa et al., 2013; Volkow et al., 2007; Volkow et al., 2009) changes in specific parts of the brain (Shire: ADHD Institute, 2014).

There are several genetic and environmental factors that increase the risk for developing ADHD. Genetically, having a relative with ADHD or having long and rare copy number variants of DNA and candidate number variants have been found to be associated with the disorder. ADHD has also been linked to being exposed to adverse circumstances as a child, such as negligence or poverty, being exposed to lead during the pre- or post-natal period, and having low birth weight or being born premature (Thapar, Cooper, Eyre, \& Langley, 2013).

Environmental factors. Recent research indicates that the use of cigarettes and alcohol during pregnancy can lead to ADHD in children (NRC on AD/HD, 2008).

Sugar. The common misconception that refined sugar leads to ADHD or makes its symptoms worse is refuted by empirical research. In one study, either sugar or 
its substitute was given to 16 boys every other day. The boys who got sugar did not behave differently and did not display different learning skills as compared with the children who received the substitute (NRC on $\mathrm{AD} / \mathrm{HD}, 2008$ ).

In another study, an average or large amount of sugar was given to 58 pre-school and school-age children as well as their families; the same results persisted (NRC on $\mathrm{AD} / \mathrm{HD}, 2008)$.

Additives. 153 3-year-old and 144 8/9-year-old children were included in a randomized, double-blinded, placebo-controlled, crossover trial. The challenge drink contained sodium benzoate and one of two artificial food color and additive mixes (A or B) or a placebo mix. According to this British research study, artificial colors or a sodium benzoate preservative (or both) in the diet relate to increased hyperactivity in 3-year-old and 8/9-year-old children in the general population (NRC on AD/HD, 2008).

\section{The Concept of Nursing}

According to the World Health Organization (2014), nursing "encompasses autonomous and collaborative care of individuals of all ages, families, groups and communities, sick or well and in all settings. It includes the promotion of health, the prevention of illness, and the care of ill, disabled and dying people."

Field of service. According to the officially published Nursing Regulation no. 27515 on March 8, 2010 by the Ministry of Health, nursing services are tasked with:

a) "Improving and protecting the health of the individual, family and group, nurturing with the aims of caring when sick and improving the quality of life, preparing and conducting the medical diagnosis and treatment plan as prepared by the doctor, creating a safe and healthy environment, roles of education, counseling, research, management, improving quality, collaboration and communication.

b) Using the skills of information, capability and decision - making as a result of vocational education, providing nursing care wherever the individuals live and work, starting from pre-natal period lasting through all life stages within professional standards and ethical principles.

c) Management of nursing services, human resources related to these services, caring environment and risk-management" (Turkish Nursing Association, 2014).

Tasks, competence, and responsibilities. In addition, the Nursing Regulation no. 27515 also stipulates that nurses: 
a) "Identify needs in relation to the health of the individual, family and society. Plan, apply, evaluate and supervise nursing care based on evidence.

b) Evaluate the quality and the results of nursing care. Make necessary improvements while providing service and report the results to the related department.

c) In applying the medical diagnosis and treatment plan, apply the written treatment provided by the doctor, accept the medical procedure of the doctor in emergency cases. Take necessary precautions with respect to the patient and staff safety.

d) Fulfill the medical demands prescribed by the doctor with respect to health care, diagnosis and treatment protocols based on scientific data.

e) Consult with the doctor in cases where the medical diagnosis and treatment procedures may give a damage to the patient. If the doctor insists on applying the procedure, keep a record of the case and apply the related procedure with the written request of the doctor.

f) Keep track of the effects of the medical diagnosis and treatment on the patient. In case of unwanted conditions, keep records and reports to the doctor. Take necessary precautions.

g) Can't leave the institution until he/she reports the necessary information verbally and in a written form to the nurse who takes over and until the nurses are no longer needed in extraordinary events such as natural disasters and accidents.

h) Carry education, counseling and research with respect to nursing. Attend to scientific events about the vocation. Support and contribute to the education of the public, student nurses, healthcare staff and candidates.

i) Take active participation in all healthcare services. Take part in the decision making processes in conducting health policies with respect to laws and regulations.

j) Take into consideration the dignity, confidentiality and the cultural values of the individual while accepting individual differences of the patients in providing service.

k) Keeps record of all procedures" (Turkish Nursing Association, 2014).

As mentioned in the items above, nurses who are competent at conducting the treatments of their patients and have adequate vocational skills, continuously make an effort in establishing the proper healthcare setting and safety. In the modern-day health-care settings, nurses often state that the environment they work in is prone to making mistakes. This observation is supported by academic research. In 1964, Schimmel found that in a sample of 240 patients who had been admitted to a university 
hospital, 20\% were somehow injured; of whom, 20\% had serious and fatal injuries. In 1974, a study based on the records of 20,000 patients at a hospital in California concluded that $4.5 \%$ of those patients went through unwanted events; $1 \%$ of which were caused by negligence (Mills, 1978, p. 360).

In 1981 , Steel found that $36 \%$ of the patients who were admitted to a teaching hospital were injured; $25 \%$ of those injured were in a critical condition and in half of those cases, the error occurred during the administration of medication (Berwick, 2006). In 1989, Gopher stated that approximately 1.7 medical errors were made for each patient being treated (Small \& Barracch, 2002). In 1991, Harvard Practice Study showed that $4 \%$ of the new admissions to a hospital in New York experienced an injury, although $69 \%$ of those cases could have been prevented (Harvard Medical Study Group, 1990). In 2000, a report published by the U.S. Institute of Medicine stated that deaths due to medical errors was the fifth leading cause nationwide. According to the report, 44,000-98,000 individuals lost their lives due to medical errors. In addition, the U.S. expenditure of medical errors totaled more than 15 billion dollars between 2000 - 2003 (CDC, 2001; Baicker, Fisher, Chandra, 2007).

The quality - control procedures that had been conducted in hospitals due to patient negligence and inattentiveness specify that the attention deficiency and hyperactivity level of nurses is an important factor in maintaining patient safety. The nurses with balanced behaviors and no ADHD often try to prevent possible mistakes and unexpected events by intervening in time. In this study, we will try to determine the attention deficiency/hyperactivity level of nurses and examine if there is a relation between their amount of work experience and their level of attention deficiency/ hyperactivity. The MOXO Distractor-Continuous Performance Test was used to determine the attention deficiency/hyperactivity level of nurses.

\section{The Moxo Distractor-Continuous Performance Test for Adults}

The MOXO Adults' ADHD Test is a computerized, distractor-continuous performance test and an objective tool which measures the attentiveness profile of an individual. In the MOXO Adults' ADHD test, there are distractors related with the environment of the individual (Neurotech, 2013).

\begin{tabular}{ll}
\hline Table 1 & \\
Summary of the MOXO Adults' ADHD Test & \\
\hline AGE RANGE & $13-70$ \\
DURATION & 18.2 MINUTES (on average) \\
FORMAT & COMPUTERIZED \\
SCORING & COMPUTERIZED \\
\hline
\end{tabular}

The MOXO Distractor-Continuous Performance Test includes four indices. 


\section{A. Attention Index}

This index evaluates the correct responses given during the presentation of a stimuli or the void period afterwards by pressing the space bar in response to the stimulus. This instrument examines the correct responses and measures one's sustained attention. The difference between the target stimuli and the correct response constitutes the errors.

\section{B. Timing Index}

This index evaluates the correct responses given when the target is on the screen. According to the National Institute of Mental Health (NIMH, 2012), the attentionrelated problems of ADHD tend to manifest as "having difficulties in being as quick and accurate as others at processing data." The MOXO distractor-continuous performance test distinguishes between the correct response with good timing during the stimulus and bad timing after the stimulus. This way of measuring attention underlines the difficulties of ADHD as suggested by the NIMH.

\section{Impulsiveness Index}

This index measures initial impulsive responses that a person gives to a non-target stimulus. The MOXO distractor-continuous performance test considers, pressing the space bar only the first time, as an impulsive response to a non-target stimulus.

\section{Hyperactivity Index}

This index measures all the different responses, except for impulsive responses. This includes, a) Excessively pressing the space bar as a response to target or nontarget stimuli due to motor hyper-responsivity, and b) Pressing any other key other than the space bar (Neurotech, 2013).

\section{Procedure}

The MOXO Adults' Distractor-Continuous Performance Test assessed 35 voluntary nurses over the course of 18 months from May 2013 to November 2014, at a private hospital. The number of participants and the level of concentration fluctuated with respect to the intensity of the nurses' work, attention, and mood, which was intensified by the fact that the assessments were usually administered during the busy Saturday and Sunday shifts.

The MOXO distractor-continuous performance test was developed in Israel and is individually administered for a fee and the process cannot be interrupted.

The results of the MOXO ADHD Test comprise two parts: the attentiveness profile and the performance graph. 


\section{The Attentiveness Profile}

This profile includes four indices: attention, timing, impulsiveness, and hyperactivity. This is a norm-referenced assessment which indicates that the individual is compared with the norm group of their age and gender. When the attentiveness profile is examined with respect to the peer group of individuals, the deviations in performance improve and the symptoms of ADHD which requires clinical attention, appear.

A - Attention. Attention includes the individual's capability to accurately assess and respond to a stimulus with respect to instructions. Individuals who have difficulties in this matter lack the ability to pay attention to small details in their environment. Such individuals have difficulty following and understanding easy or complex instructions, recognizing the small changes in their environment, and avoiding calculation errors.

T - Timing. Timing shows the individual's competence in providing the correct response in the allocated time for a task. Individuals with timing problems also have trouble in responding to the changes in their surroundings when expected. They find it difficult to complete tasks which require quick responses and to answer questions on familiar subjects in a timely manner.

I - Impulsiveness. Impulsiveness is the tendency to give a response at an inappropriate time. A person with an inclination to be impulsive will act without thinking about the existing conditions or the probable consequences of his/her behavior. That kind of behavior occurs even when the individual understands the consequences of his/ her impulsive behavior. Impulsive individuals often change the process after their first response. Finding it difficult to wait in line and committing risky behaviors without considering the consequences are common characteristics of impulsiveness.

H - Hyperactivity. Hyperactivity is characterized by finding it difficult to control muscles and refraining from undesirable behaviors like fidgeting and over-talking. Hyperactive behavior is followed by mistaken and undesirable responses. Hyperactive people are usually aware of the unwanted consequences of their behaviors but they find it hard to avoid that situation.

Individuals' profile type. Includes

- The first letter of the Attention, Timing, Impulsiveness and Hyperactivity index,

- The performance index (from 1 to 4 ) based on the standard score.

- Severity index (from 1 to 4 ) which shows the outside norm performance based on the standard score. If the standard score is within normal limits, the severity level is not expressed (Neurotech, 2013). 


\section{Data Analysis}

\section{Methods}

For each index, a standard score was measured which was categorized into four levels indicating good, standard, poor or significantly difficult performance

A standardized score of -1.65 and below was considered a below-average performance.

\section{Tables of Data}

The first table in this section is based on the individuals' norm-referenced attentiveness profile which measured attention, timing, impulsiveness, and hyperactivity. That table includes: the individual's profile type, the MOXO criteria table, and the severity table (Neurotech, 2013).

\section{The MOXO Criteria Table}

A standard score is calculated for each value and then, is divided into the four levels.

\begin{tabular}{llll}
\hline \multicolumn{3}{l}{ Table 2} \\
\multicolumn{4}{l}{ The MOXO Criteria Table } \\
\hline Level & Color & Standard Score & Notes \\
\hline 1 & Dark green & $(\mathrm{Z} \geq 0)$ & Good performance (average \& above) \\
2 & Light green & $(-0.825 \leq \mathrm{Z}<0)$ & Represents standard performance (below average) \\
3 & Yellow & $(-1.65<\mathrm{Z} \leq-0.825)$ & Indicates poor performance \\
4 & Red & $(-1.65 \geq \mathrm{Z})$ & Significant difficulties with performance. \\
\hline
\end{tabular}

The standard score for each value is displayed in third column. Performance at the first level does not fall below the average, so the standard score will always be 0 . The test is designed to determine the questionable areas rather than the high performance interval; so, the standard scores above average are not represented.

\section{Severity Table}

This table shows the low performance level of an individual, in other words, the performance at the fourth level which is significantly below average for the norm. The four stages range from 1 to 4 with a 1 , meaning "low poorness" to a 4 , indicating, "excessively low poorness." 


\begin{tabular}{lll}
\hline Table 3 & \\
\multicolumn{2}{l}{ The Table which Shows the Performance Severity Level (Neurotech, 2013) } \\
\hline Level & Level of Poorness & Quantity in Mass \\
\hline 1 & Low & $-1.95<\mathrm{Z} \leq-1.65(\% 2)$ \\
2 & Average & $-2.25<\mathrm{Z} \leq-1.95(\% 1.5)$ \\
3 & High & $-2.55<\mathrm{Z} \leq-2.25(\% 0.75)$ \\
4 & Excessive & $-2.55<\mathrm{Z} \leq-2.55(\% 0.75)$ \\
\hline
\end{tabular}

\section{The Performance Graph}

An individual's performance in the four indices is shown by the graph. The $\mathrm{X}$-Axis corresponds to eight different test stages, and the Y-Axis corresponds to the performance score ranging from 0 to 100 . The score is based on how many times the space bar is pressed.

In the assessment of Attention and Timing indices, the more the individual pressed the space bar, the higher score he/she received. In the indices of Impulsiveness and Hyperactivity, adversely, the less often an individual pressed the space bar, the higher score he/she received. In both conditions, higher score demonstrated a good performance (Neurotech, 2013).

Performance shown in real-time. Since the performance levels of the MOXO test are recorded in real time (uninterrupted attention), problems which arise at specific moments could be identified.

The levels of Basic 1 and Basic 2 were similar with the exception at the beginning as well as at the end of the test. The performances were compared and the individual's ability to sustain attention was evaluated (Neurotech, 2013).

Performance shown in different environments. While an individual was concentrating on a task, the MOXO test measured his/her ability to avoid unnecessary stimuli (selective attention).

\section{Objective}

The purpose of this study was to determine whether differences existed between the level of Attention Deficit and Hyperactivity of nurses working at a private hospital in Istanbul, with respect to the amount of their work experience 


\section{Method}

For this study, the MOXO Adults' Distractor-Continuous Performance Test was administered to 35 voluntary nurses between May 2013 to November 2014, at a private hospital.

\section{Results}

The demographic information of the 35 nurses who participated in the research study is displayed in the table below.

\begin{tabular}{llll}
\hline \multicolumn{1}{l}{$\begin{array}{l}\text { Table } 4 \\
\text { The Distribution of Nurses with Respect to their Demographic Characteristics }\end{array}$} \\
\hline \multicolumn{1}{l}{ Tables } & Groups & Frequency (n) & Percent (\%) \\
\hline Years of Age & $18-28$ & 25 & 71 \\
& $29-39$ & 7 & 20 \\
& 40 and Above & 3 & 9 \\
& Total & 35 & 100 \\
\hline \multirow{2}{*}{ Gender } & Female & 26 & 74 \\
& Male & 9 & 26 \\
& Total & 35 & 100 \\
\hline \multirow{2}{*}{ Work Experience } & Less Than / Equal to 5 Years & 22 & 63 \\
& More Than 5 Years & 13 & 37 \\
\hline
\end{tabular}

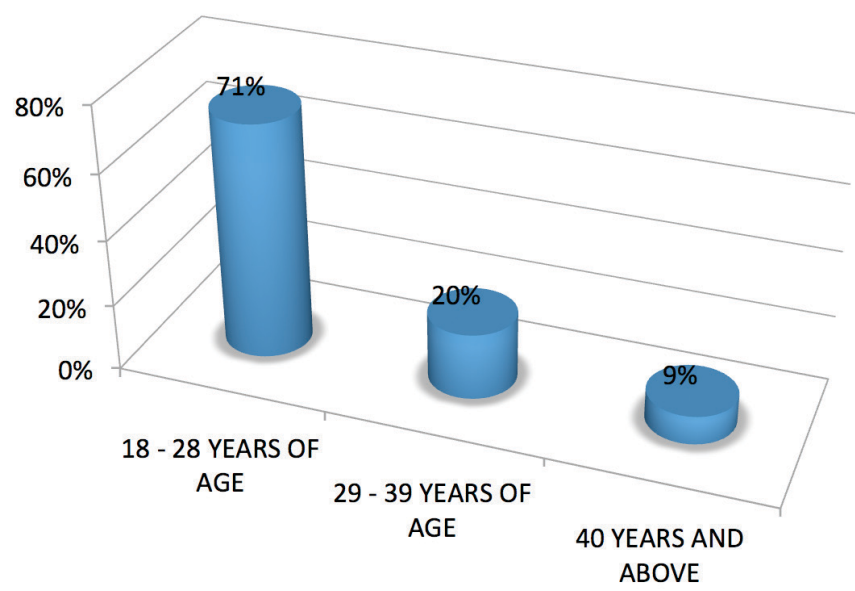

Figure 1. The age distribution of the nurses who took part in the research study.

Of total, $71 \%$ of the nurses who participated in the research were $18-28$ years old, $20 \%$ of the nurses were $29-39$ years old, and $9 \%$ of the nurses were 40 years and older. In total, $74 \%$ of the nurses in this sample were female while $26 \%$ of the nurses were male. 


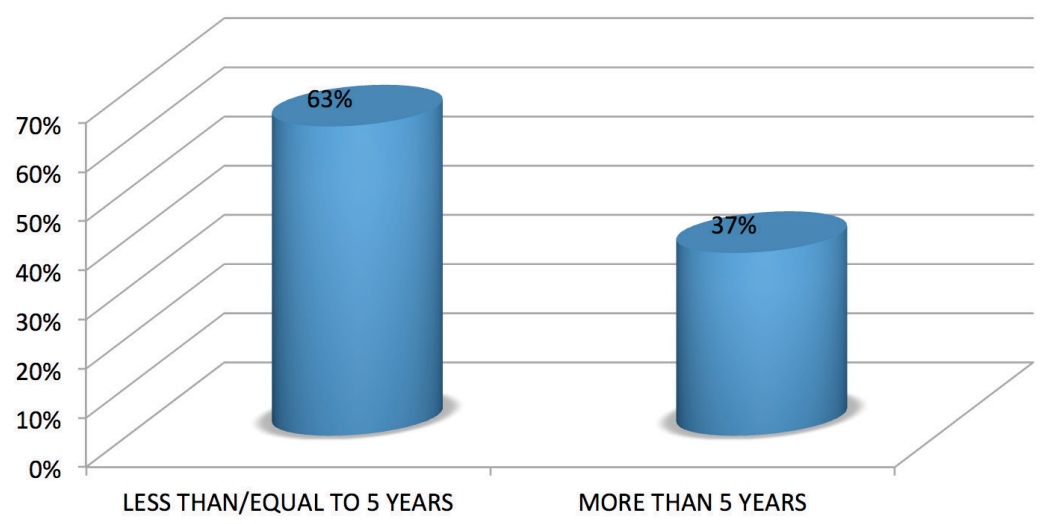

Figure 2. The amount of work experience of the nurses who took part in the research study.

$63 \%$ of the nurses in this sample had worked less than/equal to 5 years and $37 \%$ of the nurses had worked more than 5 years.

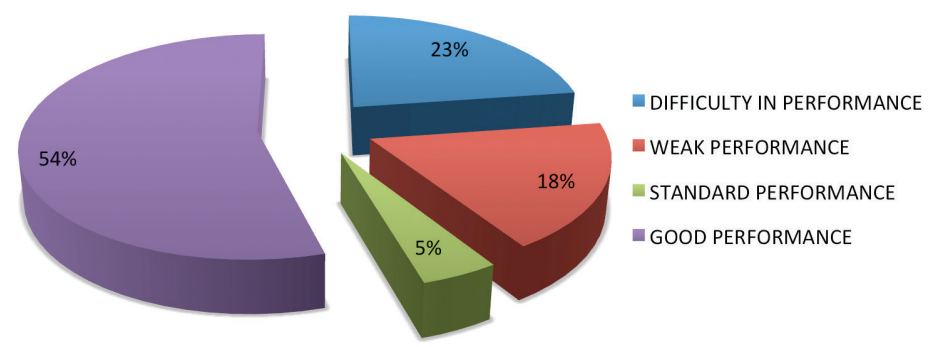

Figure 3. The attention index performance of the sample with less than/equal to 5 years of work experience.

For the attention index, $23 \%$ of the sample with work experience of less than/equal to 5 years had difficulty in performance, $18 \%$ showed weak performance, $5 \%$ had standard performance, and 54\% showed good performance.
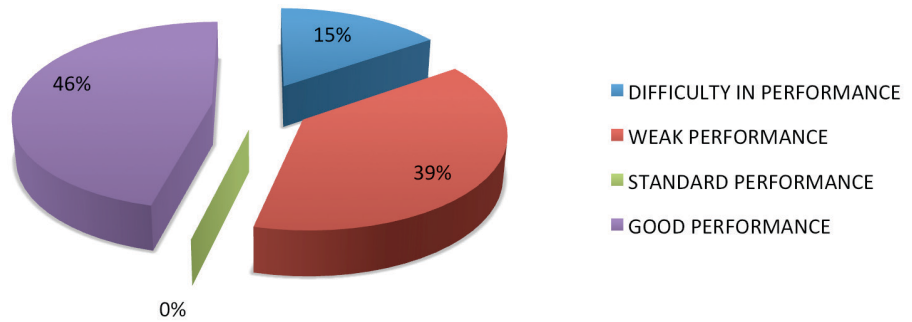

Figure 4. The attention index performance of the sample with more than 5 years of work experience. 
For the attention index, $15 \%$ of the sample with work experience of more than 5 years had difficulty in performance while 39\% showed weak performance and $46 \%$ showed good performance. Interestingly, none in this group demonstrated standard performance practices.

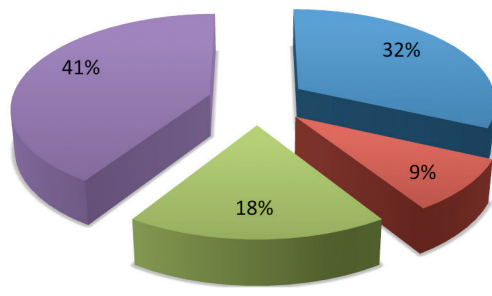

- DIFFICULTY IN PERFORMANCE

- WEAK PERFORMANCE

- STANDARD PERFORMANCE

- GOOD PERFORMANCE

Figure 5. The timing index performance of the sample with less than/equal to 5 years of work experience.

For the timing index, $32 \%$ of the sample with work experience less than/equal to 5 years demonstrated difficulty in performance, $9 \%$ had weak performance, $18 \%$ showed standard performance, and $41 \%$ showed good performance.

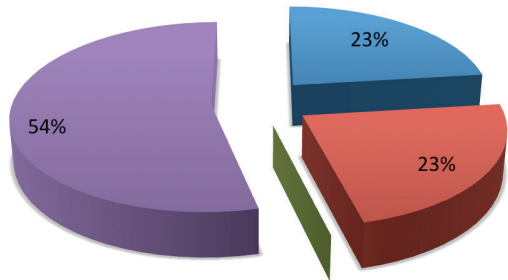

$0 \%$
- DIFFICULTY IN PERFORMANCE

WEAK PERFORMANCE

$\llbracket$ STANDARD PERFORMANCE

IGOOD PERFORMANCE

Figure 6. The timing index performance of the sample with more than 5 years of work experience.

As for the group of nurses who had 5 or more years of work experience, for the timing index, 23\% showed difficulty in performance, another $23 \%$ showed weak performance, and 54\% showed good performance. Once again, no one demonstrated standard performance in this index. 




DIFFICULTY IN PERFORMANCE

WEAK PERFORMANCE

STANDARD PERFORMANCE

GOOD PERFORMANCE

Figure 7. The impulsiveness index performance of the sample with work experience less than/equal to 5 years

For the impulsiveness index, $32 \%$ of nurses with 5 or less years of work experience had difficulty in performance, 14\% showed weak performance, $18 \%$ had standard performance, and $36 \%$ showed good performance.



$$
\begin{aligned}
& \text { "DIFFICULTY IN PERFORMANCE } \\
& \text { wEAK PERFORMANCE } \\
& \text { "STANDARD PERFORMANCE } \\
& \text { @GOOD PERFORMANCE }
\end{aligned}
$$

Figure 8. The impulsiveness index performance of the sample with work experience more than 5 years.

For the impulsiveness index, $31 \%$ of nurses with 5 or more years of work experience had difficulty in performance, $8 \%$ had weak performance, and $61 \%$ showed good performance.

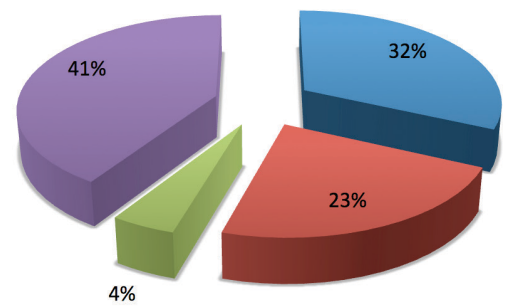

$$
\begin{aligned}
& \text { DIFFICULTY IN PERFORMANCE } \\
& \text { WEAK PERFORMANCE } \\
& \text { - STANDARD PERFORMANCE } \\
& \text { GOOD PERFORMANCE }
\end{aligned}
$$

Figure 9. The hyperactivity index performance of the sample with work experience less than/equal to 5 years.

For the hyperactivity index, $32 \%$ of nurses with 5 or less years of work experience had difficulty in performance, $23 \%$ showed weak performance, $4 \%$ showed standard performance, and $41 \%$ showed good performance. 

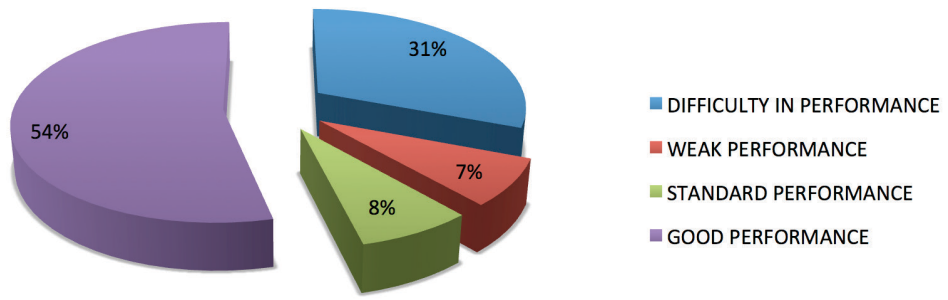

Figure 10. The hyperactivity index performance of the sample with work experience more than 5 years.

For the hyperactivity index, $31 \%$ of nurses with more than 5 years of work experience had difficulty in performance; $7 \%$ showed weak performance, $8 \%$ showed standard performance, and 54\% showed good performance.

\section{Conclusion}

The MOXO ADHD Test enables various foresights through comparing the distractors in all levels with the stage Basic 1. Those data present learning styles an individual prefers and give a chance to turn the environment he/she is in into the most appropriate way.

Taking the results of the attention index into account, more than half of the nurses with 5 or less years of work experience showed higher performance as compared with their more experienced coworkers. This suggests that the former group was more attentive.

Considering the results of the timing index, half of the nurses with more than 5 years of work experience showed higher performance as compared with their less experienced coworkers. This suggests that nurses with more than five years of work experience were more successful at time-management.

The results of the impulsiveness index indicate that more than half of the nurses with 5 or more years of work experience showed better performance as compared with the nurses having less work experience. This suggests that the former group would be able to think much better before acting and are less likely to make rash decisions.

The hyperactivity index results found that approximately half of the nurses with 5 or more years of work experience had better performance as compared with the nurses with less work experience. These conclusions indicate that the former group can control their physical movements, which could also prevent unnecessary behaviors like incessant talking and fidgeting. 
The results of this study indicate the following about the relation between work experience, attention, and hyperactivity:

The nurses with 5 or less years of work experience demonstrated more attentive behaviors whereas nurses with more than 5 years of experience showed better timing and less impulsive and hyperactive behaviors.

In order to combat the more experienced nurses' waning attentiveness, it is recommended that nurses with 5 or more years of work experience be supported with a group therapy to improve their attention skills. In addition, nurses with 5 or less years of work experience should be supported with group therapy to use worktime more efficiently, to act with conscious effort, and to control their hyperactive behaviors.

The prevention of medical errors such as patients' becoming injured, crippled, or fatally wounded must be prioritized by health supervisors. Therefore, the attention and hyperactivity levels of medical staff must be measured by tests such as the MOXO test or the Stroop test and the proper actions taken to better aid the employees of the hospital.

It is also a recommendation of the authors that the attention and hyperactivity levels of medical staff be measured and made a regular part of the job application process.

\section{References}

American Academy of Pediatrics. (2000). Clinical practice guidelines: Diagnosis and evaluation of the child with attention-deficit/hyperactivity disorder. Pediatrics, 105, 1158-1170.

American Psychiatric Association. (2000). Diagnostic and statistical manual of mental disorders: DSM IV (4th ed.). Washington DC, MD: Author.

Baicker, K., Fisher, E. S., \& Chandra, A. (2007). Malpractice liability costs and the practice of medicine in the Medicare program. Health Affairs, 26(3), 841-852.

Berwick, D. M. (2006). IHI 100K lives campaign. Retrieved June 1, 2006 from http://www.ihi.org/ IHI/Programs/Campaign/

Bhutta, A. T., Cleves, M. A., Casey, P. H., Cradock, M. M., \& Anand, K. J. S. (2002). Cognitive and behavioral outcomes of school-aged children who were born preterm: A meta-analysis. The Journal of the American Medical Association, 288, 728-737.

Castellanos, F. X., Giedd, J. N., Marsh, W. L., Hamburger, S. D., Vaituzis, A. C., Dickstein, D. P., ... Rapoport, J. L. (1996). Quantitative brain magnetic resonance imaging in attention-deficit hyperactivity disorder. Archives of General Psychiatry, 53, 607-616. 
Center for Disease Control and Prevention. (2001). National vital statistics 2001, disease data. Retrieved February 20, 2014 from http://www.cdc.gov/nchs/products/nvsr.htm

Centers for Disease Control and Prevention. (2003). Prevalence of diagnosis and medication treatment for attention-deficit/hyperactivity disorder. Morbidity and Mortality Weekly Report, 54, 842-847.

Costa, A., La Fougére, C., Pogarell, O., Moller H. J., Riedel M., \& Ettinger, U. (2013). Impulsivity is related to a striatal dopamine transporter availability in healthy males. Psychiatry Research, 211, 251-256.

Dickstein, S. G., Bannon, K., Castellanos, F. X., \& Milham, M. P. (2006). The neural correlates of ADHD: An ALE meta-analysis. Journal of Child Psychology and Psychiatry, 47, 1051-1062.

Faraone, S. V., Biederman, J., \& Mick, E. (2006). The age-dependent decline of attention-deficit/ hyperactivity disorder: A meta-analysis of follow-up studies. Psychological Medicine, 36, $156-165$.

Faraone, S. V., Perlis, R. H., Doyle, A. E., Smoller, J. W., Goralnick, J. J., Holmgren, M. A., \& Sklar, P. (2005). Molecular genetics of attention-deficit/hyperactivity disorder. Biological Psychiatry, $57,1313-1323$.

Froehlich, T. E., Lanphear, B. P., Auinger, P., Hornung, R., Epstein, J. N., Braun, J., \& Kahn, R. S. (2009). Association of tobacco and lead exposures with attention-deficit/hyperactivity disorder. Pediatrics, 124, 1054-1063.

Froehlich, T. E., Lanphear, B. P., Epstein, J. N., Barbaresi, W. J., Katusic, S. K., \& Kahn, R. S. (2007). Prevalence, recognition and treatment of attention-deficit/hyperactivity disorder in a national sample of US children. Archives of Pediatrics and Adolescent Medicine, 161, 857-864.

Grizenko, N., Fortier, M. E., Zadorozny, C., Thakur, G., Schmitz, N., Duval, R., \& Joober, R. (2012). Maternal stress during pregnancy, ADHD symptomatology in children and genotype: Gene - environment interaction. Journal of Canadian Academy of Child and Adolescent Psychiatry, 21, 9-15.

Harvard Medical Practice Study Group. (1990). Patients, doctors and lawyers: Medical injury, malpractice litigation and patient compensation in New York. Cambridge, MA: Harvard University Press.

Ivanov, I., Bansal, R., Hao, X., Zhu, H., Kellendonk, C., Miller, L., ... Peterson, B. S. (2010). Morphological abnormalities of the thalamus in youth with ADHD. The American Journal of Psychiatry, 167, 397-408.

Kessler, R. C., Adler, L., Barkley, R., Biederman, J., Conners, C. K., Demler, O., ... Zaslavsky, A. M. (2006). The prevalence and correlates of adult ADHD in the United States: Results from the National Comorbidity Survey Replication. The American Journal of Psychiatry, 163, 724-732.

Kobel, M., Bechtel, N., Specht, K., Klarhöfer, M., Weber, P., Scheffler, K. ... Penner, I. K. (2010). Structural and functional imaging approaches in ADHD. Psychiatry Research, 183, 230-236.

Kooij, J. (2013). Adult ADHD: Diagnostic treatment and assessment (3rd ed.). The Netherlands: Springer. 
Liotti, M., Pliszka, S. R., Perez, R. III., Luus, B., Glahn, D., \& Semrud-Clikeman, M. (2007). Electrophysiological correlates of response inhibition in children and adolescents with ADHD: Influence of gender, age and previous treatment history. Psychophysiology, 44, 936-948.

Mayo Clinic. (2001). Utilization and costs of medical care for children and adolescents with and without attention-deficit/hyperactivity disorder. Journal of the American Medical Association, 285(1), 60-66.

Mayo Clinic. (2002). How common is attention-deficit/hyperactivity disorder? Archives of Pediatrics and Adolescent Medicine, 156(3), 209-210.

Mills, D. H. (1978). Medical insurance feasibility study-a technical summary. The Western Journal of Medicine, 128(4), 360-363.

National Resource Center on AD/HD. (2008). What we know. The disorder named ADHD. Retrieved April 8, 2013 from https://www.chadd.org

Neale, B. M., Medland, S., Ripke, S., Anney, R. J. L., Asherson, P., Buitelaar, J. ... Biederman, J. (2010). Case-control Genome-wide Association study of attention-deficit/hyperactivity disorder. Journal of American Academy of Child and Adolescent Psychiatry, 49, 906-920.

Neale, B. M., Medland, S., Ripke, S., Asherson, P., Franke, B., Lesch, K.-P. ... Nelson, S. (2010). Meta-analysis of Genome-wide Association Studies of Attention-Deficit/Hyperactivity Disorder. Journal of the American Academy of Child and Adolescent Psychiatry, 49, 884-897.

Neurotech. (2013). MOXO Adult's ADHD Test. Retrieved May 28, 2013 from http://www.moxoadhdtest.com

Quintana, H., Snyder, S. M., Purnell, W., Aponte, C., \& Sita, J. (2007). Comparison of a Standard Psychiatric Evaluation to Rating Scales and EEG in the differential diagnosis of ADHD. Psychiatry Research, 152, 211-222.

Sagiv, S. K., Epstein, J. N., Bellinger, D. C., \& Korrick, S. A. (2013). Pre- and postnatal factors for ADHD in a nonclinical pediatric population. Journal of Attention Disorders, 17, 47-57.

Schimmel, E. M. (1964). The hazards of hospitalisation. Annals of Internal Medicine, 60, 100-110.

Shaw, P., Malek, M., Watson, B., Sharp, W., Evans, A., \& Greenstein, D. (2012). Development of cortical surface area and gyrification in attention-deficit/hyperactivity disorder. Biological Psychiatry, 72, 191-197.

Shire: ADHD Institute. (2014). ADHD etiology-genetics, neurobiology, environment. Retrieved April 27, 2014 from http://www.adhd-institute.com

Small, S. D., \& Barracch, P. (2002). Patient safety and health policy: A history and review. Hematologic Oncology North America, 16(6), 1463-1482.

Snyder, S. M., \& Hall, J. R. (2006). A meta-analysis of quantitative EEG power associated with ADHD. Journal of Clinical Neurophysiology, 23, 440-455.

Surgeon General of the United States. (1999). Mental health: A report of the surgeon general. Rockville, MD: U.S. Department of Health and Human Services.

Thapar, A., Cooper, M., Eyre, O., \& Langley, K. (2013). Practitioner Review: What have we learnt about the causes of ADHD? The Journal of Child Psychology and Psychiatry, 54(1), 3-16. 
Turkish Nurses Association. (2014). Nursing regulation. Retrieved April 8, 2014 from http://www. turkhemsirelerdernegi.org.tr/yonetmelik.aspx

U.S. Department of Health and Human Services, National Institute of Mental Health. (2008). Attention deficit hyperactivity disorder. Retrieved April 8, 2013 from http://www.nihm. nih.gov

Valera, E. M., Faraone, S., Murray, K. E., \& Seidman, L. J. (2007). Meta-analysis of structural imaging findings in attention-deficit/hyperactivity disorder. Biological Psychiatry, 61, 13-69.

Volkow, N. D., Wang, G. J., Newcorn, J., Telang, F., Solanto, M. V., Fowler, J. S. ... Swanson, J. M. (2007). Depressed dopamine activity in caudate and preliminary evidence of limbic involvement in adults with ADHD. Archives of General Psychiatry, 64, 932-940.

Volkow, N. D., Wang, G.-J., Kollins, S. H., Wigal, T. L., Newcorn, J. H., \& Telang, F. (2009). Evaluating dopamine reward pathway in ADHD: Clinical implications. The Journal of the American Medical Association, 302, 1084-1091.

World Health Organization. (2014). Nursing. Retrieved April 8, 2014 from http://www.who.int/ topics/nursing/en

\section{Appendix}

The Eight Stages of the MOXO Test

Level 1-Basic 1: There is no stimuli (the same as Basic 2).

Level 2-Visual 1: One visual stimulus appears on the screen.

Level 3- Visual 2: Two visual stimuli appear on the screen.

Level 4-Audio 1: The audio stimulus is heard by the participant.

Level 5- Audio 2: Two audio stimuli appear on the screen.

Level 6- Combo 1: One audio stimulus was coupled with an visual stimulus.

Level 7- Combo 2: Two audio stimuli were coupled with two visual stimuli.

Level 8- Basic 2: There is no stimuli (similar to Basic 1) (Neurotech, 2013). 